\title{
The Need for
}

\section{Classroom Research ${ }^{1}$}

\section{K. Patricia Cross}

Harvard Graduate School of Education

The single most important question in higher education for the rest of this decade will be, I think-What can and should be done to improve the quality of undergraduate education?

The reports that constitute the higher educational reform movement of the 1980s have taken as their major mission the improvement of undergraduate education. Most of the recommendations have to do with what is taught, i.e. the curriculum. Some seem to think that is where the problem lies-that students don't learn what they should learn in college. I am inclined to think, however, that how students are taught is even more critical. What is taught is important, but how it is taught makes the difference between a lifelong learner and a grade grubber, between enthusiasm for learning and indifference to it, between an educated society and a credentialed one.

Our educational system is based on the belief that something important happens when teachers meet students in the classroom. Most of any institution's budget is allocated to costs of instruction, and yet instruction receives very little attention from college administrators - not because we don't think it is important, but because we don't quite know what to do about a number of things. College teachers, for instance, are authorities in their disciplines. No one else at the institution knows quite as much about their particular specialties as they do, so there is an understandable reluctance to tell faculty what or how to 
teach. Moreover, we in higher education equate academic freedom with the sanctity of the classroom, and there is a tradition of restraint in probing too deeply what goes on there. And finally, there are some age-old questions that have not been answered to the satisfaction of many--What constitutes effective teaching? Who should evaluate college teachers and how? Can good teaching be recognized and rewarded?

Today's high interest in institutional assessment is one way of demanding attention to what students are learning without actually entering the classroom. Yet, what the assessors really want to know is-What are students learning in college classrooms?

Most of the reform reports are not happy with the learning that goes on in college classrooms, but the blame is generally placed, not on instructors, but on societal and institutional values that result in what might be called the Rodney Dangerfield syndrome, "Teaching don't get no respect." Faculty don't give it much respect themselves; both personal and institutional prestige are associated more with the scholarship of faculty than with the scholarship of students.

The reform reports are harsh in their criticism of these attitudes. They blame the lack of attention given to teaching on everything from "a failure of nerve and faith" and "a vacuum in educational leadership" (Bennett, 1984) to "a misguided overemphasis on research and a corresponding neglect of teaching" (Project on Redefining . . . 1985). Graduate schools are charged with the production of "too many narrow specialists" (Bennett, 1984), and with "awarding the Ph.D. degree to generation after generation of potential professors professionally unprepared to teach" (Project on Redefining . . . 1985). While there is plenty of dissatisfaction with the quality of instruction, there are few constructive suggestions for what to do about it.

Part of the problem, I think, is that there are two unexamined assumptions that underlie most of the educational reform movement. The first is that educational reform consists of making large highly visible policy decisions - the installation of statewide testing or incentive systems, for example, or the appointment of blue-ribbon commissions to study curricular reform. There is very little attention given to the potential impact of thousands of small classroom reforms that might add up to real and substantial change. Somehow we have convinced ourselves 
that there is more power in making decisions than in implementing them. So we worry about involving professors in policy decisions, but we fail to consider what each teacher acting in his or her own classroom might do to achieve reform.

The second assumption of the current educational reform movement is related to the first. We assume that if we really want action, it must come from the top-that state legislators, campus administrators or some other authority should assume responsibility for creating a system of rewards and punishments that will shape the behavior of those we want to change--in this case college teachers.

Most of the reform reports assume, for example, that if the rewards for teaching were greater, more time and attention would be given to instruction, and it would improve. Without denying that greater rewards, more attention, and more value placed on teaching would undoubtedly help, it is by no means certain that we really know what to do to improve teaching. The notion that greater rewards will improve teaching assumes that professors know how to teach well, but are not doing so because there are other things more rewarding.

I am going to assume, for the purposes of getting this discussion off the ground this morning, that this is an ideal world, that the big dramatic policy decisions have been made, and that good teaching will be appropriately rewarded. Now what?

First we have to decide what good teaching is. We are not exactly novices in discussing and researching that question. There is an extensive literature on what makes a good teacher. Basically, there are three ways to describe effective teachers: 1) we can describe their characteristics-training, experience, knowledge of subject matter, etc.; 2) we can describe their behaviors in the classroom-whether they ask provocative questions, call students by name, encourage discussion; and 3) we can describe what students are able to do as a result of the teacher's efforts-how much they know, how well they think, their attitudes toward learning. In short, the literature consists of descriptions of input, process, and output variables. The criterion problem is present, of course, in all of these approaches. That is, in order to describe what a good teacher is, or does, or accomplishes, we need to know how we are defining a "good" teacher. A little reading of the literature on this issue quickly drives one to paraphrase the Supreme Court justice commenting 
on pornography, "I can't define good teaching, but I know it when I see it."

Well, maybe that is not such a bad position to take. All of us can identify good and poor teachers on our own campuses, and when researchers go onto a campus and start asking students, faculty, and administrators to identify the best teachers on campus, it doesn't take long to come up with a list that shows rather high agreement.

Much of the agreement, of course, comes from the hearsay of student comments on teachers and courses. In recent years, "hearsay" has been formalized into systematic student ratings, and student evaluations of teaching have been widely adopted nationwide. In a recent survey, Peter Seldin (1984) found that 98 percent of four-year liberal arts colleges claimed that classroom teaching is a "major factor" in evaluating faculty, and more than two-thirds said that student evaluation is "always used" in evaluating teaching. That represents substantial growth in recent years in confidence in student evaluations; just over half of the colleges were as dependent on student ratings in 1978.

To the credit of higher education, the use of student ratings increased in proportion to the positive findings from research on the reliability and validity of student evaluations. Although researchers can still manage to raise reservations and new questions for study, I think the judgment is fairly well in by now. Students are reliable observers; they have ample opportunity to see teachers in action on good days and bad, and they are in a good position to evaluate the impact of the teaching on themselves as learners.

Moreover, the evidence suggests that student ratings have good validity, i.e. that students tend to rate most highly those courses in which they learn the most. Centra (1977) found correlations in the .60's and .70's between scores on final exams and student ratings of "overall teaching effectiveness" and "value of the course." While one can still find reported correlations ranging from negative to high positive, the tilt of comprehensive, well-designed studies - and the more recent metaanalyses (Cohen, 1982)--is clearly toward significant positive correlations between student achievement and positive course ratings.

Another test of the validity of student ratings is to relate 
student evaluations to teacher behaviors in the classroom. Murray (1985) found that teachers who received high student ratings did, according to neutral classroom observers, teach differently from teachers receiving low ratings. Highly rated teachers were well-organized, expressive, interacted more with students, related subject matter to student interests and in general demonstrated the behaviors that students report for good teachers.

Students also tend to be reliable and relatively unbiased raters. There is no evidence to support the myths that popular teachers are mere showmen, that alumni will find virtues in professors that were not respected ten years earlier, that teachers who are tough graders will receive low ratings, or that agreement on the identity of good teachers is difficult to achieve (Gaff and Wilson, 1971).

One answer to those who are ready to reward good teaching if it can be identified is that students know good teaching when they see it. But students can go further; they can describe the characteristics and behaviors of good teachers. The research, by this time, is fairly consistent on what students consider important factors in effective teaching. Feldman (1976) reviewed a group of studies in which students were asked to describe "good" or "ideal" or "best" teachers. He found eight characteristics that were usually ranked high in all studies: concern for students, knowledge of subject matter, stimulation of interest, availability, encouragement of discussion, ability to explain clearly, enthusiasm, and preparation. There is nothing at all surprising about his findings. These characteristics turn up over and over again in one form or another when students are asked to describe good teachers.

Factor analytic studies of student rating forms show rather similar clusters of characteristics. Feldman (1976) reviewed nearly 60 factor analytic studies and concluded that there were three major clusters in effective teaching-the instructor's ability to present the material, to encourage students to learn, and to regulate and deal fairly with students. Kulik and McKeachie (1975) reviewed eleven factor analytic studies of teacher rating scales and found similar factors which they labeled as follows: "Skill," which represents the ability to communicate in an interesting way, to stimulate intellectual curiosity, and to explain clearly; "Rapport" which involves empathy, interaction 
with and concern for students; "Structure" which concerns organization and presentation of course material, and "Overload" which refers to the workload and instructor demands (Abrami, 1985).

I find all of this quite credible, and I have no difficulty believing that teachers who have these characteristics not only rate high with students, but probably are good teachers. Since student evaluations are far and away the most common form of teacher evaluation at the college level, teacher effectiveness is currently being defined and determined by a combination of researchers, who decide which items should go into the rating scales, and by students who decide which items will be important.

The next five years will probably see the rapid growth of another set of judges and definers of good teaching. The movement toward assessment of student learning-for surely it can be called "a movement" by now-purports to use student outcomes as the measure of educational effectiveness. At worst, this will put the definition and reward of good teaching in the hands of external agencies who will decide what students should know and how it is to be measured. At best, it will call attention to the goals of instruction and how well they are being accomplished. Statewide testing of student achievement is certainly on the increase, and while it is quite unlikely to determine an individual teacher's future, it is possible that teachers will be encouraged to "teach to the test." If the test really measures what students should learn in college, that may not be all bad, but few have that much confidence in our current measures of learning.

The assessment movement underway now has ambitious goals but quite modest accomplishments. Almost everyone would like to measure a wide range of student outcomes, affective as well as cognitive, to develop in teachers the insight and motivation for instructional self-improvement, and to integrate assessment into the instructional process. However, what we have to date in most places is the measurement of a narrow band of fairly low-level cognitive skills. While current practices seem a long way from the ideal, the search for better measures must be undertaken. Assessment is the first step to improvement.

Yet a third set of judges of the criteria for teaching effectiveness are educational researchers. Educational researchers go about determining teacher effectiveness in a variety of ways. 
They count; they observe; they conduct experiments; they write ethnographic or naturalistic descriptions; they survey other people. While some would claim that researchers don't determine the criteria for teaching effectiveness and that their task is to describe what exists without imposing their own values on the data, that is not what really happens.

The major value that researchers impose on the search for criteria of teaching effectiveness is that the findings must be generalizable, that is to say, not specific to any particular classroom. The methods of traditional social science research-sampling, tests for significance, control of variables, and the like-are devised largely to prune out situation-specific influences, leaving those characteristics common to all or most effective teachers. Yet, some of the most effective teachers any of us can remember were effective because their unique characteristics worked in very specific situations. The search for criteria for teaching effectiveness that has been conducted with considerable energy and earnestness by researchers over the past decade is helpful in showing us what effective teachers have in common, but it masks some of the most useful information, specifically any insight into how individuals with their infinite variety and unique values and interests develop into effective teachers in a situation-specific classroom.

I have taken some time to review the current status of research on the criteria for evaluating the quality of instruction because I want now to talk about what's missing and how we can find it and apply it to the improvement of undergraduate instruction.

The first thing that is missing from the literature is some good discussion of what teachers are trying to accomplish. Students, legislators, and researchers all have entrees to defining the criteria for good teaching. But, in my survey of some 200 articles and books on college teaching, I came across only two studies that asked teachers what they wanted students to learn from them. True, teachers serve on committees to develop achievement tests; they serve on curriculum committees; they are frequently polled regarding hours spent in class preparation, perceived rewards for teaching, and attitudes about the policies of their institutions. But they are rarely asked what they are trying to do in their own classrooms.

A classic study by Axelrod (1976) found that even among 
the relatively homogeneous population of humanities' teachers in 4-year colleges, teachers were aiming for vastly different outcomes. Some taught to the goal of mastery of subject matter. Some worked to help students develop higher level cognitive skills such as synthesis, analysis, and evaluation. Some were more interested in the personal development of their students, while others tried to model for their students the well-educated mind at work.

Studies of teaching goals in community colleges would probable reveal additional goals. Some teachers are trying to teach job-entry skills, some have the building of self-confidence and self-respect as their first priority. Some feel strongly that the greatest service they can render is to see that students learn the basic skills of communication.

The first step then, I should think, in improving undergraduate instruction is to find out what teachers are trying to do. If that is not what they should be doing or if their aspirations are not high enough, that's one thing. But if they do not or cannot accomplish the goals they set for themselves, then that is a different problem.

The second element that is missing from the literature on effective teaching is a constructive approach to applying research to improve practice. I specify "constructive approach" because, over the years, there has been criticism of practitioners for their failure to use research, on the one hand, and criticism of researchers for their failure to work on useful questions, on the other. But $I$ think the gap between research and practice is the fault of neither.

Social science research, with its search for general truths that hold across all classrooms, is not designed to address the situation-specific questions that teachers have. What a teacher needs to know is how his or her behavior affects the learning of a known group of students, studying a specific learning topic, under known conditions. By and large, the purpose of educational research is to push back the frontiers of knowledge and to build the foundations for understanding. John Dewey (1929, p. 19) wrote almost sixty years ago that, "no conclusion of scientific research can be converted into an immediate rule of educational art." Research on teaching and learning is simply too large and complex to extract findings that can be easily disseminated to teachers as rules to improve teaching practices (Fenstermacher, 1982). 
Donald Schön (1983) contends in his provocative book entitled The Reflective Practitioner that research has done little to improve practice in any of the professions. In fact, he says, universities pursue "a view of knowledge that fosters selective inattention to practical competence and professional artistry" (p. vii). He calls for us to put aside the notion that "intelligent practice is an application of knowledge to instrumental decisions" (p. 50) and instead to help professionals gain insight into their practice through an ongoing process of reflecting on what they know, articulating their intuitive thinking, and seeking feedback about the results of practice.

Schőn's concept of reflective practice offers helpful new perspectives on the use of knowledge to improve practice. I continue to think it is both possible and desirable for teachers to collect and use both "hard" and "soft" data on student learning. However, research designed for the improvement of teaching should be situation-specific, and it should provide immediate and useful feedback on what students are learning as an aid to reflective practice.

Situation-specific research may, at first blush, appear to result in knowledge with extremely limited usefulness to the profession of teaching, but my guess is that the exchange of knowledge from many specific classrooms will give teachers more useful insight into the teaching/learning process than the search for generalizations across a "representative sample" of students, teachers, and subject matters.

The third thing that is missing is a literature on how to conduct research in and on the classroom, with its inevitable variations in teachers, students, and subject matter. An articulate group of critics of traditional educational research is beginning to be heard promoting various alternatives, such as ethnographic research, naturalistic inquiry, action research, qualitative methods, and reflective practice (See, for examples, Guba, 1979; Guba and Lincoln, 1981; Eisner, 1980, 1984; Argyris, et al. 1985; Schön, 1983; Stiggins, 1985). This is a scattered but promising development, one that should add valuable perspectives to the search for knowledge about teaching and learning.

But naturalistic inquiry, ethnographic research, and the other new alternatives to quantitative, experimental research, for all their value-and it is considerable-are not the answer 
to a research approach to the improvement of teaching either. Many of their rules and conventions are no more applicable to the improvement of classroom practices than those of quantitative and experimental research. Naturalistic evaluation, for example, requires "lengthy and prolonged" engagement by a highly trained researcher (Williams, 1986), and part of the value of ethnography comes from the notion that findings should "evolve" from the study rather than be interpreted as "answers" to questions formulated by researchers (Smith, 1982).

Perhaps we could simply work harder and write more (perish the thought) to fill in the missing pieces that I have identified from my review of the literature on effective teaching, but I suggest that it is time to develop a different approach, specifically designed for what we want to accomplish, namely, the improvement of undergraduate instruction. I believe that it is time to give classroom teachers more responsibility for doing the type of research that will improve their own teaching. I call this Classroom Research. The purpose of classroom research is to help the teacher evaluate his or her effectiveness as a teacher and to foster intellectual stimulation and professional renewal. The concept of classroom research springs from six basic assumptions:

1) That the quality of student learning is directly related to the quality of instruction.

2) That teachers need to know what their students are learning in their classrooms.

3) That inquiry and intellectual challenge are sources of professional renewal for teachers.

4) That the research most likely to improve instruction is that conducted by classroom teachers formulating and investigating questions that they want answered.

5) That self-improvement is most likely to result from specific feedback relevant to one's own goals and behaviors.

6) That there is nothing so mysterious or esoteric about research on college teaching that it cannot be done by anyone capable of teaching at the college level.

I suggest that the implementation of classroom research should begin with experienced teachers in the field, but I also 
think that every graduate student planning to teach any subject in any college should demonstrate competency in conducting investigations into the effectiveness of his or her own teaching. New graduate courses need to be designed, new methods devised, new perspectives developed. Let me give some concrete examples of what some possible classroom research projects might look like.

First, I would like to give an example of the contrast between how a classroom researcher and a traditionally trained researcher might approach a similar problem. Let us assume that the problem is the familiar one of dropouts. In the traditional studies of dropouts that we all know so well, the researcher selects representative samples of dropouts and persisters, and after collecting data from student records, determines the differences between persisters and dropouts, inevitably concluding that dropouts come from lower socioeconomic backgrounds, made lower grades in high school, work more hours off campus, are commuters, and have lower educational expectations.

While these findings are verified so frequently by researchers that we have to conclude that they are indeed factors in dropping out of college, all of the factors identified are what Ben Bloom (1980) would call "unalterable variables." There is nothing that educators can do to change them.

Now let us see how a classroom researcher might study this problem. Let us assume that our classroom researcher is curious about the dropout problem, decides to interview some students who stopped coming to class, and finds out that a certain amount of discouragement sets in as the semester's work begins to build. As she reflects on this observation, it occurs to her that she usually hits her stride as a teacher about the fifth week of the semester and feels ready to tackle some of the more difficult units about that time. She notes that the high dropout in her own classes occurs about five weeks into the school year, and she concludes that she might try a number of things in her own classroom to reduce needless dropouts-perhaps give an especially satisfying assignment, maybe rework or reschedule the difficult unit, maybe call in a few students and talk with them about the unit or about the class, perhaps offer special encouragement, make a referral, drop a note, make a call.

The procedure of the classroom researcher is to formulate the question, collect data, reflect on classroom practices, try a 
solution, and evaluate the results. There is nothing especially new about those methods; they are frequently recommended for huge well-funded projects that can afford longitudinal " $R$ and D." The difference is that teacher motivation is enhanced through classroom research because the question for study is framed by the teacher, and implementation is facilitated because there is no gap between "researcher" and "practitioner."

Faculty meetings might well be planned around classroom research projects to share data, perceptions, and possible solutions. The emphasis in faculty meetings should be on the use of data and systematic observation; discussion might appropriately range from sharing useful and creative approaches to gathering data, to data analysis, to recommendations for possible changes in policies and practices within the department. Academic departments have come back into style with the arrival of the assessment movement. There is considerable merit in setting departmental goals for student learning that are consistent with institutional goals. But the contributions of the physics department may differ from those of the history department. Institutional goals are far more likely to be accomplished if teacherscollectively in departments and individually in classrooms-determine what they can offer to collegiate learning and assess how well they are accomplishing their part.

Classroom research projects may also be of primary interest to an individual teacher. I think, for example, that teachers need a set of "feedback devices" that will tell them how students are responding to classroom procedures. Examples of this sort of project are numerous. Perhaps the teacher wants to know whether a "review session" prior to the mid-term helps in long-term retention or is only useful for immediate test score gains. Or perhaps the teacher is interested in knowing whether a field trip is worth the effort in changing attitudes about a particular social problem-or would reading about it or discussing it or seeing a dramatization on videotape do as well or better? Maybe a math teacher, interested in teaching a particular math concept, reads about another teacher's method and decides to test it in his own classroom.

The projects for classroom research are limited only by teachers' imaginations. While the examples I have presented do not generally call for complicated methodologies or analyses, there is nothing to prevent interested teachers from studying 
very complex learning problems. Mina Shaughnessy's (1977) contribution to the improvement of student writing was arrived at through sitting down with hundreds of beginning writers and sensitively observing individual struggles with the writing process.

In conclusion, I think it is time to get classroom teachers involved in the study of teaching and learning. They should be intellectually curious about it as well as professionally involved in the improvement of their own teaching practices. While classroom research can be done now by any teacher with the appropriate curiosity and motivation, I believe that if classroom research is to help all of us, there should be standards for the quality of the research.

I am working now on the development of a graduate course in classroom research. Its primary purpose would be to help teachers assess student learning as it occurs in the classroom. One important unit of the course involves learning about "feedback devices" which may range from oral responses to teacher questions designed to assess class progress to more complex measures of cognitive skills to student reactions to teaching procedures. You could be of great help to me if you would write out any feedback devices that you know about and mail them to me.

I am also interested in collecting samples of course evaluation forms currently in use. Some of the items are potential clues to student self-assessments of learning and to student reactions to classroom procedures. As such, they serve as valuable feedback devices to inform classroom teachers about student reactions while there is still time to use the information for the benefit of that class. I hope that you might also be willing to send me course evaluation forms used in your college.

I suspect that no one knows quite as much about the realities of improving instruction as the members of this group, the Professional and Organizational Development Network in Higher Education. But I think we have just started to scratch the surface in improving college-level teaching.

I conclude where I began. The improvement of undergraduate instruction is on the agenda now, and your work is all important. 


\section{REFERENCES}

Abrami, Philip C. (1985). Dimensions of effective college instruction. Review of Higher Education, 8(3), 211-228.

Argyris, Chris, Putnam, Robert and Smith, Diana M. (1985). Action science. San Francisco: Jossey-Bass.

Axelrod, Joseph. (1976). The university teacher as artist. San Francisco: Jossey-Bass.

Bennett, William J. (1984). To reclaim a legacy. Washington, D.C.: National Endowment for the Humanities.

Bloom, Benjamin S. (1980). The new direction in educational research: Alterable variables. Phi Delta Kappan, February, 382-385.

Centra, John A. (1977). The how and why of evaluating teaching. New Directions for Higher Education, 17, 93-107.

Cohen, Peter (1982). Validity of student ratings in psychology courses: A research synthesis. Teaching of Psychology, 9(2).

Dewey, John. (1929). The sources of a science of education. New York: Liveright.

Eisner, Elliott. (1980). Toward a conceptual revolution in evaluation. Educational Forum, 44(3), 373-374.

. (1984). The art of educational evaluation: $A$ personal view. London and Philadelphia: The Falmer Press.

Feldman, Kenneth A. (1976). Grades and college students' evaluations of their courses and teachers. Research in Higher Education, 4, 69-11.

Fenstermacher, Gary D. (1982). On learning to teach effectively from research on teaching effectiveness. Journal of Classroom Interaction, $17(2), 7-12$.

Gaff, J. G. and Wilson, R. C. (1971). The teaching environment. AAUP Bulletin, 475-493.

Guba, Egon G. (1979). Naturalistic inquiry. Improving Human Performance Quarterly, 8(4), 268-276.

Guba, E. G. and Lincoln, Y. S. (1981). Effective evaluation: Improving the usefulness of evaluation results through responsive and naturalistic approaches. San Francisco: Jossey-Bass.

Kulik, J. A. and McKeachie, W. J. (1975). "The evaluation of teachers in higher education." In F. N. Kerlinger (Ed.), Review of Research in Education, Vol. 3. Itasca, Ill: F. E. Peacock.

Murray, Harry G. (1985). "Classroom teaching behaviors related to college teaching effectiveness." J. G. Donald, A. M. Sullivan (Eds.), Using research to improve teaching. New Directions for Teaching and Learning. 23, 21-34.

Project on Redefining the Meaning and Purpose of Baccalaureate Degrees (1984). Integrity in the college curriculum. Washington, D. C.: American Association of Colleges. Reprinted in The Chronicle of Higher Education, February 13, 1985. 
Shaughnessy, Mina (1977). Errors and expectations. New York: Oxford Press.

Schon, Donald A. (1983). The reflective practitioner. New York: Basic Books.

Seldin, Peter (1984, April). "Faculty surveying policy and practicies." Change, 29-33.

Smith, Louis M. (1982). "Ethnography." Encyclopedia of educational research, 5th ed., Vol. 2. New York: The Free Press, 587-592.

Stiggins, Richard J. (1985, October) "Improving assessment where it means the most." Educational Leadership, 43(2), 69-74.

Williams, David D. (1986, Spring) "Naturalistic evaluation: Potential conflicts between evaluation standards and criteria for conducting naturalistic inquiry." Educational Evaluation and Policy Analysis, $8(1), 87-99$.

\section{NOTE}

1. This manuscript was prepared with funding from the National Center for Research to Improve Postsecondary Teaching and Learning (NCRIPTAL). The project reported herein was performed pursuant to a grant from the Office of Educational Research and Improvement/ Department of Education (OERI/ED). However, the opinions expressed herein do not necessarily reflect the position or policy of the OERI/ED and no official endorsement by the OERI/ED should be inferred. 